\title{
A study on physical physiology of men's 110-meter hurdle project.
}

\author{
Yimin Chen ${ }^{*}$, Lingyan Liu ${ }^{2}$ \\ ${ }^{1}$ Department of Sports, Shenyang University of Technology, Liaoning Shenyang, PR China \\ ${ }^{2}$ Social Sciences Research Center, Shenyang Sport University, Liaoning Shenyang, PR China
}

\begin{abstract}
Men's 110 meter hurdles are closely related to sports physiology. Therefore, firstly, sports physiology theory was discussed, then, the development of China's men's 110 meter hurdles project was analyzed, finally, through the method of mathematical statistics and from the perspective of sports physiology, Men's 110-meter hurdles were studied, so as to provide some reference for the continuous improvement of hurdle technology. The results show that the promotion of Chinese men's 110-meter hurdle movement should be appropriately increased from the distance, keep the low-arc trajectory of vacant movement and shorten the distance from the lower column.
\end{abstract}

Keywords: Man, 110 meter hurdles, Sports physiology.

Accepted on April 25, 2017

\section{Introduction}

Men's 110-meter hurdles are at the leading position in the track and field hurdles, this makes more and more scholars at home and abroad begin to study the hurdle project physical and psychological aspects of the subject [1]. Studies have shown that the level of high-performance column technology in men's 110 -meter hurdles is closely related to the strength of the human ankle joint, physical coordination and vacancy time. The results of this study further validate the close relationship between hurdle technology and sports physiology [2]. Therefore, firstly, sports physiology theory was expounded, then the analysis model was discussed, finally the men's 110 meter hurdles project development and physiology, based on the analysis of the data obtained, kinematics index hurdle was analyzed and research, therefore, the direction of hurdle technology for men's 110 meter hurdles was pointed out.

\section{State of the Art}

Based on the theory of sports physiology and the application of mathematical statistics, this paper analyzes and studies the men's 110 meter hurdles. Mathematical statistics method is mainly through the observation of the frequency of some phenomena to find the inherent law of the phenomenon, and make a certain degree of accuracy and prediction. Mathematical statistics is widely used in natural science, engineering technology, management science and Humanities and social sciences. With the continuous improvement of mathematical statistics, in the course of the study, scholars at home and abroad continue to analyze and study various research objects with the information technology.

\section{Methodology}

In all hurdles, the performance and level of our men's 110meter hurdles are very prominent. Figure 1 is the men's 110 meter hurdles. Liu Xiang won the 110 meter hurdles in the Athens Olympic Games, which represents the leap development of the men's 110 meter hurdles [3].
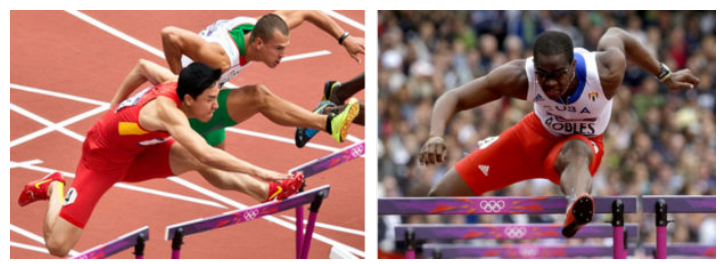

Figure 1. Men's 110 meter hurdles.

Using the method of mathematical statistics, the author constructs a physiologic analysis model to analyze and study the continuous improvement of men's 110-meter hurdles and hurdles. The main methods include numerical calculation and graphics rendering. Both of these methods can be applied to SPSS descriptive statistical analysis software for specific data processing and analysis.

$r=\frac{\sum X Y-\frac{\sum X \sum Y}{N}}{\sqrt{\left(\sum X^{2}-\frac{\left(\sum X\right)^{2}}{N}\right)\left(\sum Y^{2}-\frac{\left(\sum Y\right)^{2}}{N}\right)}} \rightarrow(1)$

Descriptive statistics is a basic statistical method of sorting, categorizing, simplifying, or plotting the data obtained from the study into a graph to describe and summarize the relationship between the characteristics of the data and the variables. The descriptive statistics mainly involve the 
concentration trend, the degree of discretization and the correlation intensity of the data. The most commonly used indicators are the mean, the standard deviation, the correlation coefficient, etc. [4].

$s=\operatorname{sqrt}\left(s^{\wedge} 2\right) \rightarrow(2)$

Among them, the correlation coefficient and the standard deviation of the formula are the formula (1) and formula (2). Combining the practice of the hurdle project, this paper constructs the kinematic analysis model of the man 110 meters hurdle project. Firstly, the mathematical statistics function was used to analyze the frequency distribution of the data. Then, the results of the analysis were analyzed. Finally, the conclusion of the data was obtained based on the analysis results, and the effective ideas of improving the hurdle technology were put forward.

\section{Result Analysis and Discussion}

The results obtained from the analysis of men's 110-meter hurdles by means of mathematical statistics and exercise physiology are as given in Table 1 .

Table 1. Kinematics index analysis of effective hurdle.

\begin{tabular}{llllll}
\hline Object & $\begin{array}{l}\text { Step } \\
\text { distance }\end{array}$ & $\begin{array}{l}\text { Next step } \\
\text { distance }\end{array}$ & $\begin{array}{l}\text { Center } \\
\text { gravity } \\
\text { height }\end{array}$ & $\begin{array}{l}\text { Lifting } \\
\text { angle }\end{array}$ & $\begin{array}{l}\text { Hurdle } \\
\text { step } \\
\text { length }\end{array}$ \\
\hline A & 1.87 & 1.60 & 0.16 & 69 & 3.47 \\
\hline B & 1.75 & 1.73 & 0.17 & 68 & 3.48 \\
\hline C & 2 & 1.58 & 0.18 & 66 & 3.58 \\
\hline D & 1.79 & 1.78 & 0.17 & 65 & 3.57 \\
\hline
\end{tabular}

It can be seen from Table 1 that the distance of the upper column, the distance of the next step, the center of gravity and the length of the hurdles are in the process of the hurdle race. The data show that the distance between the 1.7 and 1.8 meters of the athletes is a certain distance from the standard of the world elite athletes. While there is a relationship among the hurdle distance, the athlete's body center of gravity volatility, vacancy speed and angle. As can be seen from Figure 2, the average distance of the test athletes from the cross-angle of 67 or so, it is greater than the world's top athletes from the crossangle average of about 6 degrees, from the cross-angle over the center of gravity to move the arc is too large, resulting in hurdles slow pace.

The data show that the distance between the lower reaches of the test athletes is between 1.6 and 1.8 meters, much higher than the distance of the world's elite athletes, which largely affects the athlete's center of gravity and thus the athlete's rhythm have a negative impact. To sum up, from the physiological point of view, China's men's 110 meter hurdle technology promotion should be appropriate to increase the low trajectory across the distance, keep moving vacated and appropriate to shorten the distance under the bar. In the process of training, our men's 110 meter hurdler hurdle will be according to the characteristics of the flight time and flight trajectory as the focus of training.

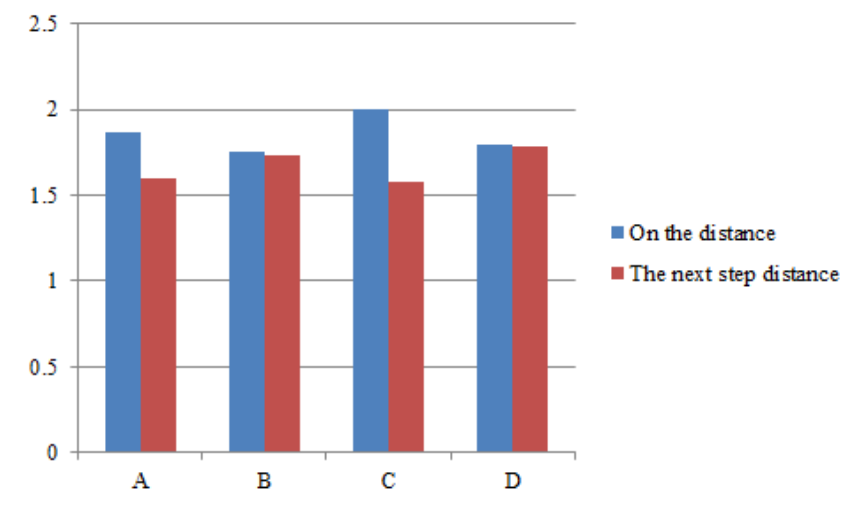

Figure 2. Comparison of the kinematics indexes of men's hurdles in the 110 meter hurdles.

\section{Conclusions}

It is very important to study the sports physiology of the men's 110 meter hurdles. Therefore, in this paper, through the application of mathematical statistics model, the Chinese men's 110 meter hurdles were analyzed and studied. Firstly, sports physiology theory was discussed, then, the development of China's men's 110 meter hurdles project was analyzed, finally, from the physiological point of view and through the methods of mathematical statistics, men's 110 meter hurdles project was investigated, so as to continuously enhance the technical hurdles for providing some reference. The results show that China's men's 110 meter hurdle technology promotion should be appropriate to increase the low trajectory across the distance, keep moving vacated and appropriate to shorten the distance under the bar. In addition to run technology to boost the hurdles from the technical point of application of sports physiology, the author thinks that we should actively improve the environment of China's men's 110 meter hurdles project, so as to promote the continuous development of China's hurdles project.

\section{Acknowledgement}

This work is supported by the Liaoning provincial social science planning fund project, the development of Liaoning Province four league effective way, L14DTY018.

\section{References}

1. Birch E, Carter A, Boyd J. An examination of jump kinematics in dogs over increasing hurdle heights. Comparative Exercise Physiol 2016; 12L: 1-8.

2. Anderson BE, Neumann ML, Huxel Bliven KC. Functional movement screen differences between male and female secondary school athletes. J Strength Condition Res 2015; 29: 1098-1106.

3. https://en.wikipedia.org/wiki/ Athletics_at_the_2004_Summer_Olympics $\%$ E2\%80\%93_Men\%27s_110_metres_hurdles 
A study on physical physiology of men's 110-meter hurdle project

4. https://www.socialresearchmethods.net/kb/statdesc.php

\section{*Correspondence to}

Yimin Chen

Department of Sports

Shenyang University of Technology

PR China 